\title{
Comparison of Adaptive Behaviour among Children with Learning Difficulties
}

\author{
Cassandra Rani Peter*, Samuel Chan \\ Faculty of Education and Social Sciences, Raffles University Iskandar, Johor Bahru, Johor, Malaysia \\ *Corresponding author: cassandra.rani@raffles-rui.com
}

\begin{abstract}
The objective of this study is to explore the nature of adaptive behaviour in terms of fine and gross motor skills in children with learning difficulties. This research aims to find whether there are any differences between the fine and gross motor skills among the children from the age of four to fourteen with learning difficulties. This study used Vineland Adaptive Behaviour Scales Classroom Edition survey questionnaire to explore the differences in the adaptive behaviour of children with learning difficulties in the motor skills domain. A quantitative within-participants experimental design was employed to assess the adaptive behaviour among children with learning difficulties in motor skill domain. The independent variable was the motor skills consisting of two levels which are the fine motor skills and gross motor skills. The dependent variable was the difference in adaptive behaviour of the children with learning difficulties. Paired-samples t-test was used to study the differences between the variables. It was evident that the paired sample t-test conducted implied that there was no significant difference between the variables which are the fine and gross motor skills. Future researchers could also compare other demographic factors such as age, gender or cultural background that influences the adaptive behaviour of children with learning difficulties in various domains besides motor skills such as socialisation and communication domains.
\end{abstract}

Keywords: Adaptive behaviour; motor skill; learning difficulties

(C) 2017 Penerbit UTM Press. All rights reserved

\subsection{INTRODUCTION}

Hido and Shehu (2010) highlighted that students with learning difficulties were being stigmatised as children who were lazy, incompetent, school dropouts and many more. However, the term learning difficulties has been defined in various literatures for the past forty years and it had been explained beyond those descriptions assumed by the community. For instance, some of the common definitions described by the researchers were those who experience academic failure, lack of organisational skills, having poor cognitive skills as well as having intellectual disabilities (Bechtel, 1973; Kane, Roy \& Medina, n.d.; Thoma et al., n.d.). Ideally, learning difficulties were known to be a symptom of developmental disorders and some of the common disorders that exhibit the symptoms were dyslexia, attention deficit hyperactivity disorder, autism, language impairment and many others (Nicolson \& Fawcett, 2006; American Psychiatric Association, 2013).

Individuals with learning difficulties or intellectual difficulties experience a challenge to adapt in the working life once they have grown up and were also prone to poverty (Thoma et al., n.d.; Wagner, Newman, Cameto, Garza \& Levine, 2005). Nevertheless, individuals with learning difficulties could adapt to the social environment with proper training and practice which might help them to overcome the problem faced by individuals with learning difficulties. Some of the training that could be provided to those individuals are table manners, communication, motor as well as socialisation skills (Nihira, 1970; Manohari, Raman \& Ashok, 2013). Thus, the current study aims to explore and compare the adaptive behaviour especially the motor skills among children with learning difficulties.

Gillott (1999) has conducted studies on autistic children and those with language disorder to assess their anxiety level as well as their social worries by using Vineland Adaptive Behavior Scales in the domains of communication and socialisation. The findings of this study indicated that autistic children did better than children with language disorder in communication domain whereas the results were vice versa for the socialisation domain. Thus, this study implies that autistic children were more adaptive in communication while their counterpart were more adaptive in socialization domain. Additionally, researchers have also conducted studies on deaf children to explore the implication of cochlear implantation on the motor skills of those children and other studies include assessing the effect of motor skills on cognitive ability among children aged 6-11 years old (Horn, Pisoni \& Miyamoto, 2006; Piek, Dawson, Smith \& Gasson, 2008). Based on the study conducted by Horn, Pisoni and Miyamoto (2006) on deaf children, it was found that the scores from Vineland Adaptive Behaviour Scales for gross motor skills tend to increase with age whereas the scores decreases with age for fine motor skills.

To further explore regarding the topic of motor skills, this study will assess and compare the motor skills on children with learning difficulties. Precisely, the research aims to find whether there is any differences between the fine and gross motor skills among the children with learning difficulties from the age of four to fourteen. Thus, the research objective is to identify whether there is any difference in adaptive behaviour of fine and gross motor skills among children with learning difficulties. Since the focus of the current study is to explore the nature of adaptive behaviour in terms of fine and gross motor skills in children with learning difficulties, the variables under 
investigation were the motor skills which are the fine and gross motor skills. Thus, this research study will be searching for any differences in adaptive behaviour between fine and gross motor skills among children with learning difficulties.

\subsection{THEORETICAL FOUNDATION OF THE STUDY}

Adaptive behaviour will be assessed in motor skill domains among other domains which are communication, daily living skills and socialisation domain as motor skill domain was found to be more pertinent to this study (Sparrow, Cicchetti, \& Balla, 2005). Motor skills domain is divided into two sub domains which are gross motor skills and fine motor skills. The assessment of motor skills will be conducted on children with learning difficulties.

\section{Adaptive Behaviour}

Adaptive behaviour is a term that has been used by various researchers although it is not a well defined term as researchers tend to focus on the assessments used to measure adaptive behaviour rather than defining the term operationally (Eldevik, Eikeseth, Jahr \& Smith, 2006; Fidler, Hepburn \& Rogers, 2006; King, 2007). The term adaptive originates from the root word adapt. Conceptually, adapt refers to the learning process of altering and changing a behaviour according to a situation to suit oneself better through experiences (Berkhout, Hertin \& Gann, 2006). Operationally, adaptive behaviour refers to the specific behaviours carried out by an individual involving motor skill to be able to work out the daily routines in life. In this research, the motor skills are assessed in terms of fine as well as gross motor skills.

\section{Gross Motor Skills}

Conceptually, gross motor skills refer to the mobile ability by using hands and legs (Sparrow, Cicchetti, \& Balla, 2005). Operationally, student with learning difficulties will be assessed in terms of the ability to perform gross motor skill such as walking up stairs, running, jumping and hopping.

\section{Fine Motor Skills}

Conceptually, fine motor skills refer to the ability to operate items using hands and fingers such as screwing, using eraser and cutting and screwing (Sparrow, Cicchetti, \& Balla, 2005). Operationally, student with learning difficulties will be assessed in terms of the ability to perform fine motor skills such as building three dimensional structures, turning and pulling doorknobs, marking and drawing.

\section{Children with learning difficulties}

Conceptually, individuals with learning disorders has been referred to as having the symptoms of difficulties learning and using academic skills such as maths, reading and writing as well as interference with daily routine (American Psychiatric Association, 2013). Operationally, children with learning difficulties in this study were children with the age range from 4-14 years old with or without neurological disorder having the symptoms of communication and social deficit and not able to express their feelings and intentions verbally. Other symptoms that operationally define children with learning difficulties include experiencing difficulty in learning a subject area pertaining to academic skills due to lack of attention which is unlike the learning pattern of other children of their age.

\subsection{CONCEPTUAL FRAMEWORK}

Adaptive behaviour has been studied and assessed by many researchers in different areas. Some of those studies are adaptive behaviour to overcome harmful situations, intellectual disability and adaptive behaviour, behavioural adaptation in animals as well as in the areas of physical, language, and social adaptation (Prasher, 1995; Pitcher, Misund, Ferno, Totland \& Melle, 1996; Patja, Livanainen, Vesala, Oksanen \& Ruoppila, 2000; Roberts, 2006). Manohari, Raman and Ashok (2013) described adaptive skills as skills that are used to carry out daily activities by means of an individual ability. This implies that although individuals with autism spectrum disorder tend to exhibit symptoms such as social withdrawal, these individuals could exhibit other adaptive skills such as having good motor skills to help themselves in their daily chores (Fombonne, 2003; American Psychiatric Association, 2013).

Fidler, Hepburn and Rogers (2006) conducted a study to assess children aged 2-3 years old diagnosed with Down syndrome to explore the typical behaviour using the Vineland Adaptive Behaviour Scale (VABS) as well as the Mullen Scales of Early Learning (MSEL). The author mentioned that the information regarding the child's adaptive behaviour was obtained from the parents through interview. In terms of the motor skills of the adaptive behaviour, the researchers did not distinguish the performance between the fine and gross motor skills but instead compared the mean scores of motor skills with other domains of VABS. Their results indicated that the children with Down syndrome had a lower mean score in the motor skills domain compared to other domains which are communication, daily living skills and socialisation. Nevertheless, the mean scores for fine and gross motor skills based on the MSEL implied that the children with Down syndrome tend to exhibit poor motor coordination in the gross motor activities as compared to the fine motor activities.

Similarly, Piek, Dawson, Smith and Gasson (2008) conducted a study to assess the motor skills among 33 children without any developmental disorder consisting of 16 girls and 17 boys from the age of 6 to 11 years. However, the study was conducted among children without any developmental disorder. The authors utilised the McCarron assessment of neuromuscular development (MAND) to assess the fine and gross motor skills among the children and the results mean score indicated that the children did better in the fine motor skills compared to the gross motor skills. Szatmari, Archer, Fisman, Streiner, and Wilson (1995) conducted a study on 68 children aged from 4 to 6 years old diagnosed with either autism or Asperger's syndrome to assess their adaptive behaviour in terms of communication, 
socialisation and activities of daily living as well as verbal and non-verbal cognitive skills. In this study, the researchers utilised the VABS scale survey edition to assess the adaptive behaviour. The mean scores of adaptive behaviour in the motor skill domain indicated that scores given by the parents and the teachers contradicted for children with autism and Asperger's syndrome. Precisely, means scores of motor skills domain by parents was higher for children with Asperger's syndrome compared to the children with autism whereas the mean scores by the teachers was higher for children with autism compared to the children with Asperger's syndrome. Thus, this study will explore the differences between the fine and gross motor skills among the children with learning difficulties.

\subsection{METHODOLOGY}

\section{Research Design}

This study used Vineland Adaptive Behaviour Scales Classroom Edition survey questionnaire to explore the differences in the adaptive behaviour of children with learning difficulties (Sparrow, Balla, \& Cicchetti, 1984). Among the four domains of survey questionnaire which are communication, daily living skills, socialisation and motor skills domain, only the motor skill domain was utilised to explore the research questions.

A quantitative within-participants experimental design was employed to assess the adaptive behaviour among children with learning difficulties in motor skill domain. The independent variable was the motor skills consisting of two levels which are the fine motor skills and gross motor skills. The dependent variable was the adaptive behaviour of the children with learning difficulties.

Within-participants experimental design was conducted instead of between-participant design as every participant were assessed in every levels of the independent variable and therefore fewer participants is needed to conduct this research (Dancey \& Reidy, 2011). Besides that, confounding variables such as individual differences which might have an effect on the outcomes of the study could be reduced by conducting within-participant design as single participant will be tested on both levels of the independent variable instead of two participants for every level of the independent variable (Field, 2013). Furthermore, in order to overcome order effects that might influence the outcomes of the study, the task presented to the participants to assess the fine and gross motor skills were counterbalanced (Dancey \& Reidy, 2011).

A cross-sectional study was conducted using the questionnaire. The experimenter conducted the activity for every task in the questionnaire individually to every student to assess their motor skills in both construct. There were 23 questions in total whereby there were 10 questions for gross motor skills construct and 13 questions for fine motor skills construct. The experimenter observed the ability of the participant to conduct the activity presented or told to do and rated according to their performance. The objects or toys used for the study were educational tools from Able Land Education centre.

\section{Participants}

Students with learning difficulties from Able Land Exceptional Centre with the age range from 4-14 years old were recruited to be the participants in this study. The sampling method used was purposive sampling, precisely criterion sampling whereby the study was only conducted on students with learning difficulties in Able Land Exceptional Centre (Palys, 2008).

The participants with learning difficulties in this study consisted of fifteen participants with developmental disorder such as autism spectrum disorder, Down syndrome, microcephaly and hydrocephalus as well as those without any developmental disorder but only had learning difficulties. These participants were classified as experiencing learning difficulties as they have communication and social deficit, not able to express their feelings and intentions verbally and not able to make decisions in their life as children of their age would normally do. Other symptoms of these participants with learning difficulties include experiencing difficulty in learning a subject area pertaining to academic skills due to lack of attention which is unlike the learning pattern of other children of their age.

\section{Research Instrument}

Vineland Adaptive Behaviour Scales (VABS) was used to conduct the current study. VABS is an assessment commonly used by researchers to assess adaptive behaviour among children below the age of 13 (Eldevik, Eikeseth, Jahr \& Smith, 2006; King, 2007). The author also added that the scale has been extended to conduct assessment on students up to the age of 18 years and it is not limited for only individuals with learning difficulties but instead generally for any individuals 18 years and below (King, 2007).

According to Nihira (1970), adaptive behaviour scale is an evaluation used to assess those with developmental disorders. The scale assesses the level an individual is able to be independent and carry themselves well in a social setting without any assistance (Nihira, 1970). Additionally, the author also mentioned that individuals with developmental disorders were usually assessed based on their intelligence quotients (IQ) prior to the adaptive behaviour scale. Hence, using the adaptive behaviour scale enables researchers to provide proper placement or training for those with developmental disorders.

The VABS is a scale administered to a participant usually a caregiver or a teacher who is familiar with the daily activities of the individual being assessed and there are three versions of the revised Vineland which are the Interview Edition Survey Form, the Expanded Interview Edition and the Classroom Edition (Sparrow, Balla, \& Cicchetti, 1984).

Four domains of adaptive behaviour are measured which are the communication, daily living skill, socialisation and motor skills. In the current study, the Classroom edition was employed and the only the motor skill domain was assessed to meet the aims of the study. There are two constructs in the motor skills domain which are fine motor skills and gross motor skills.

In the current study, the items in the motor skills domain of the Vineland Adaptive Behavior Scale was revised from the original version to better facilitate the assessment conducted. Some of the parts of the scale had been revised by omitting some items in the scale. Details and justifications of the revision are illustrated in Table 1. 
Table 1 Parts of VABS scale that has been revised

\begin{tabular}{|c|l|l|}
\hline Motor skill & \multicolumn{1}{|c|}{ Omitted items } & \multicolumn{1}{|c|}{ Justification } \\
\hline Fine & None of the items were omitted & $\begin{array}{l}\text { All the items in this domain could be administered } \\
\text { for assessment. }\end{array}$ \\
\hline \multirow{6}{*}{ Gross } & $\begin{array}{l}\text { Runs smoothly, with changes in speed and direction } \\
\text { (for example runs while attempting to catch a ball) }\end{array}$ & $\begin{array}{l}\text { Safety of the participants was prioritised and thus } \\
\text { this item was omitted to prevent any injury due to } \\
\text { accidents while running. }\end{array}$ \\
\cline { 2 - 3 } & $\begin{array}{l}\text { Climbs both in and out of bed or steady adult chair } \\
\text { without assistance }\end{array}$ & $\begin{array}{l}\text { The bed was not available in the location of the } \\
\text { study whereas the steady adult chair could not be } \\
\text { used by all the participants due to age differences. }\end{array}$ \\
\cline { 2 - 2 } & $\begin{array}{l}\text { Climbs on low play equipment (for example swings, } \\
\text { seesaws, or small slides) }\end{array}$ & $\begin{array}{l}\text { The equipments were not available in the location } \\
\text { of the study (Able Land Exceptional Centre). }\end{array}$ \\
\cline { 2 - 2 } & $\begin{array}{l}\text { Climbs on and off high play equipment (for } \\
\text { example, monkey bars, jungle gyms, trees, or } \\
\text { fences) }\end{array}$ & \\
\cline { 2 - 3 } & $\begin{array}{l}\text { Pedals tricycle or other three-wheeled vehicle for at } \\
\text { least six feet }\end{array}$ & \\
\cline { 2 - 3 } & $\begin{array}{l}\text { Rides bicycle without training wheels, without } \\
\text { falling }\end{array}$ & \\
\hline
\end{tabular}

Table 1 demonstrates the parts of the revised VABS scale and the justification for the revision. Thus, after the revision there were 10 items in the gross motor skills domain and 13 items in the fine motor skills domain.

Some of the examples of the items being assessment for gross motor skill domain include being able to walk steadily, walking up and down the staircase by putting both feet on each step as well as to walk with alternating feet, jumping over the small object such as a stick, hopping on one foot without falling and hopping forward without losing balance, rolling ball while sitting as well as catching soft ball thrown from a distance.

Examples of items being assessed for fine motor skill domain include being able to screw and unscrew the lid of a container. Other activity include being able to build three dimensional structures by using at least five blocks. Besides that, participants will also be assessed on the ability to open door that require pushing or pulling as well as by turning and pulling doorknobs. Moreover, other assessment of fine motor skill include completing jigsaw puzzle of at least 6 pieces, drawing, using eraser without tearing the paper, open and closing scissors by using one hand and cutting along a straight line and even complex pictures.

Each of the VABS domains has a mean of 100 and a standard deviation of 15 whereby high scores indicates better adaptive skills (Sparrow, Balla, \& Cicchetti, 1984; Szatmari et al., 1995). The total scores from the ratings are added up to obtain the score for every domain. Table 2 below shows the original number of items in the VABS scale, the number of items omitted for this study as well as the total number of items used in this study after the revision. Since there are 10 items for the for the gross motor skill domain, the minimum score that could be obtained is 0 and the maximum score is 20 . For the fine motor skill domain whereby there are 13 items, the minimum score that could be obtained is 0 and the maximum score is 26 .

Table 2 Number of items revised from the VABS scale

\begin{tabular}{|c|c|c|c|}
\hline MOTOR SKILLS & $\begin{array}{c}\text { ORIGINAL NUMBER } \\
\text { OF ITEMS }\end{array}$ & $\begin{array}{c}\text { NUMBER OF ITEMS } \\
\text { OMITTED }\end{array}$ & $\begin{array}{c}\text { NUMBER OF ITEMS } \\
\text { USED IN THIS STUDY }\end{array}$ \\
\hline Gross & 16 & 6 & 10 \\
\hline Fine & 13 & 0 & 13 \\
\hline
\end{tabular}

\section{Procedure}

Ethical approval was obtained from the institution prior to conducting the study. Following on, participants were recruited by asking the teachers working with the children with learning difficulties of the potential participant who was able to participate in the study. Precisely, the students needed to meet the criteria of having learning difficulties. After the potential students who will be participating in the study were recruited, a consent form was provided to the Able Land education centre for allowing the study to be conducted on their students as well as to use their tools to conduct the study.

The tools needed to conduct the study were prepared prior to conducting the studies on the participant. The experimenter allocated the studies to be conducted on 3 to 4 participants each day as every participant requires an approximate time of 30 minutes to carry out the activities. The participant was isolated in a separate room or play area to avoid any distractions that might affect the results. The motor skills domain of the revised Vineland Adaptive Behaviour Scale was then be administered to every participant individually. These were administered in a conversation format between the experimenter and the participant. The experimenter gave instructions to the participant regarding the task that needed to be done for assessment. The assessment for gross motor skills and fine motor skill were conducted randomly to prevent any order effects that might influence the results of the study.

The experimenter rated the performance of the participant. The rating scale was scored from a range of 0 to 2 whereby the rating of 0 indicates the participant never do the activity, rating of 1 indicates the participant sometimes or partially does the activity and a rating of 2 indicates that the participant does the activity. The activities conducted were similar for all students in all age groups.

After the assessment has been conducted on every student, the data obtained was analysed in terms of age group and outcome of the study was interpreted. Following on, the outcome of the study was discussed and compared with previous research and finally a conclusion 
was developed at the end of the report which discusses about the limitations of the current study as well as future directions for future researchers.

Paired-samples t-test was used to look at the differences between the variables Paired sample t-test was used instead of independent sample t-test as this study had within-participant experimental design (Field, 2013). Besides that, paired sample t-test was used as there were only two variables involved in this study which are fine and gross motor skills.

\subsection{RESULTS AND DISCUSSION}

The VABS was conducted on fifteen students with learning difficulties. Paired-samples t-test was used to look at the differences between the variables. Paired sample t-test was used instead of independent sample t-test as this study had within-participant experimental design (Field, 2013). Besides that, paired sample t-test was used as there were only two variables involved in this study which are fine and gross motor skills.

Table 3 Mean scores of variables

\begin{tabular}{|c|c|}
\hline Variables & Mean of total scores \\
\hline Fine Motor Skill & $13.8(\theta=5.72, \mathrm{n}=15)$ \\
\hline Gross Motor Skill & $15.2(\theta=8.91, \mathrm{n}=15)$ \\
\hline
\end{tabular}

The total scores that could be achieved in the fine motor skills domain were 20 whereas the total score that could be obtained in the gross motor skills were 26 . Based on the table 3 , it is evident that the mean of total scores for fine motor skills was 13.8 whereas the mean of total scores for gross motor skills was 15.2. Although it is apparent that the mean scores for gross motor skills was higher compared to the scores for the fine motor skill, it could not be inferred that gross motor skills were more adaptive than fine motor skills among individuals with learning difficulties as the number of items assessed in variable were different. Hence, further analyses were needed to be conducted to explore the relationship between the variables.

In order to find the differences between scores in fine and gross motor skills domain, a two samples repeated-measures design paired t-test was conducted. The results are described in Table 4

Table 4 Differences between the scores of fine and gross motor skills using t-tests

\begin{tabular}{|c|c|c|c|c|c|c|c|}
\hline \multirow[t]{2}{*}{ Variables } & \multirow[t]{2}{*}{ Mean } & \multirow[t]{2}{*}{$\begin{array}{c}\text { Std. } \\
\text { Deviation }\end{array}$} & \multicolumn{2}{|c|}{$\begin{array}{l}\text { 95\% Confidence Interval of the } \\
\text { Difference }\end{array}$} & \multirow[t]{2}{*}{$\mathbf{t}$} & \multirow[t]{2}{*}{ df } & \multirow[t]{2}{*}{ Sig. (2-tailed) } \\
\hline & & & Lower & Upper & & & \\
\hline Fine & 13.8 & 5.7 & & & & & \\
\hline Gross & 15.2 & 8.9 & & & & & \\
\hline Fine - Gross & & & -3.491 & 0.691 & -1.436 & 14 & 0.173 \\
\hline
\end{tabular}

Based on Table 4, although it is evident that that participants in the fine motor skills condition scored a mean of 13.8 as opposed to the mean of 15.2 in the gross motor skills condition, the $95 \%$ confidence limits show us that, if we repeated the experiment, the population mean difference between the conditions would lie somewhere between -3.491 and 0.691 . Thus it is not certain that, in the population, the motor skills scores would give better result. This difference in scores of fine and gross motor skill was not significant among individuals with learning difficulties $(t(14)=-1.436 ; \mathrm{p}>0.05)$. Hence, these paired sample t-test demonstrate non-significant within subject differences on these two aspects of motor skills which are fine and gross motor skills.

The value of $p$ which was 0.173 was more than 0.05 which implies that there was no significant difference between the fine and gross motor skills scores among individuals with learning difficulties in this study. Based on Table 4.2, the standard deviation for gross motor skills is 8.9 which were greater than the standard deviation for fine motor skills which was 5.7. This indicates that there was more variability in scores for gross motor skill as compared to fine motor skill.

The statistical analysis found that there were no significant differences between the variables which are the fine and gross motor skills. This result is contradicting with the studies conducted by Piek et al. (2008) as well as the studies conducted by Fidler, Hepburn and Rogers (2006) as those researcher's results indicated that the children did better in fine motor skill domain compared to the gross motor skills domain. The differences in the result could be due to two factors which are the type of assessment conducted. Piek et al. (2008) utilised the McCarron assessment of neuromuscular development (MAND) and Fidler, Hepburn and Rogers (2006) utilised the Mullen Scales of Early Learning (MSEL) whereas this study utilised the Vineland Adaptive Behaviour Scale (VABS) classroom edition to explore the research questions.

Another factor that led to the contradicting results is due to the sample selection. This is because Piek et al. (2008) conducted their study on children without any learning difficulties and Fidler, Hepburn and Rogers (2006) conducted their study only on children diagnosed with Down syndrome whereas this study was conducted on children with learning difficulties which consisted of children having developmental disorder as well as those without any developmental disorder but only experiencing learning difficulties.

Based on the study conducted by Szatmari et al. (1995), it was found that the assessments for motor skills domain was rated by both the parents and teachers and results indicated that there were contradicting outcome in scores for children with autism and Asperger's syndrome. This is because the rating given by the parents resulted in higher score for children with Asperger's syndrome whereas the 
rating given by the teachers resulted in higher score for children with autism. In this current, the results could not be compared similar to the study conducted by Szatmari et al. (1995) because this study was only rated by a single researcher.

\section{Limitations and Future Directions}

This research was conducted only on 15 participants and this had led to sampling error because this research was unable to recruit sufficient participants with learning difficulties to represent the target population (Dancey \& Reidy, 2011). Precisely, having few participants could also produce a sample mean that might be an overestimation of the population mean (Dancey \& Reidy, 2011). Thus, the results of this study could not be generalised to the whole population.

Apart from that, there were extraneous variable which the researcher was unable to control such as the age, gender as well as the diagnosis of the participants which could have potentially influenced the outcome of the study.

Moreover, pilot study was not conducted for this research as there was lack of participants in this study and if the pilot study was conducted on the same students participating in the actual study it would have an influence on the results of the study as the participants might be prone to practice effects. Due to this reasons, pilot study was not conducted for this research.

Another limitation of this study is regarding the instrument used which is the Vineland Adaptive Behaviour Scale (VABS) classroom edition. The challenge faced while administering this assessment is to obtain the inter-rater reliability. Due to having only one examiner to rate the performance of the participants in this study, the results obtained might be prone to bias as the examiner might incorrectly rate the performance of the participant without proper observation as mentioned by Wells et al. (n.d.).

Additionally, since there is only one examiner, the examiner herself had to communicate with the children while administering the assessment. Thus, the examiner had to communicate with the participants and some of them were unable to communicate and the examiner was unsure whether the children understood what he or she was supposed to do. At times, the examiner had to demonstrate the activity to be conducted by the participants to make sure they understood what they had to do and this could also have influenced the results of the study.

Future researchers are recommended to control the confounding variable such as the age, ethnicity, gender as well as the diagnosis of the participants while conducting the assessments such as the Vineland Adaptive Behaviour Scale and to recruit sufficient number of participants to participate in the study to obtain accurate results that would be able to reflect the population.

Additionally, it is also essential to make sure that there is more than one examiner filling up the assessment for every participant to avoid biased results as well as to increase the inter-rater reliability. Having multiple examiners will also increase the reliability of the tests and therefore incorrect results could be avoided.

Future researchers could consider exploring the factors that cause the child with learning difficulties to perform differently in the tasks assessing the motor skills. Moreover, future researchers could also compare other demographic factors such as age, gender or cultural background that influences the adaptive behaviour of children with learning difficulties in various domains besides motor skills such as socialisation and communication domains.

\subsection{CONCLUSION}

As a summary, this study had demonstrated that children with learning difficulties are also able to exhibit adaptive behaviour that could eventually lead them to carry themselves well in the society. This study has also explored various children having learning difficulties due to their developmental disorder such as autism spectrum disorder. Hence, more studies should be conducted to ensure proper diagnosis and placement for children with learning difficulties.

\section{References}

American Psychiatric Association. (2013). Diagnostic And Statistical Manual Of Mental Disorders (5 ${ }^{\text {th }}$ ed.). Washington, DC: Author.

Bechtel, L.P. (1973). The Detection And Remediation Of Learning Disabilities (Progress Report). Department of Health, Education, and Welfare, Washington, DC. Berkhout, F., Hertin, J., Gann, D. M. (2006). Learning to Adapt: Organisational Adaptation To Climate Change Impacts. Climatic Change, 78, 135-156.

Dancey, C.P., \& Reidy, J. (2011). Statistics Without Maths For Psychology (5 ${ }^{\text {th }}$ ed.). England: Pearson Education Limited.

Eldevik, S., Eikeseth, S., Jahr, E., \& Smith, T. (2006). Effects of Low-Intensity Behavioural Treatment For Children With Autism And Mental Retardation. Journal of Autism and Developmental Disorders, 36(2), 211-224.

Fidler, D. J., Hepburn, S., \& Rogers, S. (2006). Early Learning And Adaptive Behaviour In Toddlers With Down Syndrome: Evidence For An Emerging Behavioural Phenotype? Down Syndrome Research and Practice, 9(3), 37-44.

Field, A. (2013). Discovering Statistics Using IBM SPSS Statistics $\left(4^{\text {th }}\right.$ ed.). Thousand Oaks, California: Sage Publications.

Fombonne, E. (2003). Epidemiological Surveys Of Autism And Other Pervasive Developmental Disorders: An Update. Journal of Autism and Developmental Disorders, 33(4), 365-382.

Gillott, A. (1999). Anxiety in High Functioning Children With Autism (Doctoral dissertation). Retrieved from ProQuest Dissertations and Theses database. (UMI No. U120192).

Hido, M., \& Shehu, I. (2010). Beyond Stigmatization Of Children With Difficulties In Learning. US-China Education Review, 7(10), 70-77.

Horn, D. L., Pisoni, D. B., \& Miyamoto, R. T. (2006). Divergence of Fine And Gross Motor Skills In Prelingually Deaf Children: Implications For Cochlear Implantations. Laryngoscope, 116(8), 1500-1506.

Kane, S.T., Roy, S., \& Medina, S. (n.d.). Identifying College Students At Risk For Learning Disabilities: Evidence For Use Of The Learning Difficulties Assessment In Postsecondary Settings. Journal of Postsecondary Education and Disability, 26(1), 21-33.

King, M. G. (2007). Extending the Classroom Vineland. Australian Journal of Education \& Developmental Psychology, 7, 92-97.

Manohari, S. M., Raman, V., \& Ashok, M. V. (2013). Use of Vineland Adaptive Behavior Scales - II in Children With Autism - An Indian Experience. Journal of Indian Association Child Adolescent Mental Health, 9(1), 5-12.

Nicolson, R. I., \& Fawcett, A. J. (2006). Procedural Learning Difficulties: Reuniting The Developmental Disorders?. Trends in Neurosciences, 30(4), 135-141.

Nihira, K. (1970). Person-Clusters In Two Dimension Of Adaptive Behaviour. U.S. Department of Health, Education and Welfare.

Palys, T. (2008). Purposive sampling. The Sage Encyclopedia of Qualitative Research Methods. Sage: Thousand Oaks, CA, 2, 697-698. 
Patja, K., Livanainen, M., Vesala, H., Oksanen, H., \& Ruoppila, I. (2000). Life Expectancy Of People With Intellectual Disability: A 35-Year Follow-Up Study. Journal of Intellectual Disability Research, 44(5), 591-599.

Piek, J. P., Dawson, L., Smith, L. M. \& Gasson, N. (2008). The Role Of Early Fine And Gross Motor Development On Later Motor And Cognitive Ability. Human Movement Science, 27, 668-681.

Pitcher, T. J., Misund, O. A., Ferno, A., Totland, B., \& Melle, V. (1996). Adaptive Behaviour Of Herring Schools In The Norwegian Sea As Revealed By HighResolution Sonar. ICES Journal of Marine Science, 53, 449-452.

Prasher, V. P. (1995). Epilepsy and Associated Effects On Adaptive Behaviour In Adults with Down syndrome. Seizure, 4, 53-56.

Roberts, A. C. (2006). Primate Orbitofrontal Cortex And Adaptive Behaviour. Trends in Cognitive Sciences, 10(2), 83-90.

Sparrow, S.S., Balla, D. A., \& Cicchetti, D.V. (1984). Vineland Adaptive Behavior Scales (Survey Form). Circle Pines, MN: American Guidance Service.

Sparrow, S. S., Cicchetti, D. V., \& Balla, D. A. (2005). Vineland-II Adaptive Behavior Scales: Survey Forms Manual. Circle Pines, MN: AGS Publishing.

Szatmari, P., Archer, L., Fisman, S., Streiner, D. L., \& Wilson,F. (1995). Asperger's Syndrome And Autism: Differences In Behaviour, Cognition, And Adaptive Functioning. Journal of American Academy of Child and Adolescent Psychiatry, 34(12), 1662-1671.

Thoma, C. A., Lakin, K. C., Carlson, D., Domzal, C., Austin, K., \& Boyd, K. (n.d.). Participation in Postsecondary Education For Students With Intellectual Disabilities: A Review Of The Literature 2001-2010. Journal of Postsecondary Education and Disability, 24(3), 175-191.

Wagner, M., Newman, L., Cameto, R., Garza, N., \& Levine, P. (2005). After High School: A First Look At The Postschool Experiences Of Youth With Disabilities. National Longitudinal Transition Study 2, 1-190. 